Running head: STEREOTYPE THREAT AND SELF-AFFIRMATION

\author{
Combating Stereotype Threat: \\ The Effect of Self-affirmation on Women's Intellectual Performance \\ Andy Martens, Michael Johns, and Jeff Greenberg \\ University of Arizona \\ Jeff Schimel \\ University of Alberta
}

Reference:

Martens, A., Johns, M., Greenberg, J., \& Schimel, J. (2006). Combating stereotype threat: The effect of self-affirmation on women's intellectual performance. Journal of Experimental Social Psychology, 42, 236-243.

Address correspondence to:

Andy Martens

University of Arizona

Psychology Department

P.O. Box 210068

Tucson, AZ 85721-0068

E-mail: andym@u.arizona.edu

Phone: (520) 904-2597

Authors' Note: We thank Richard Fuller and Branden Seedall for their help with this project.

\begin{abstract}
The present studies were designed to investigate the effects of self-affirmation on the performance of women under stereotype threat. In Study 1, women performed worse on a difficult math test when it was described as diagnostic of math intelligence (stereotype threat condition) than in a non-diagnostic control condition. However, when women under stereotype threat affirmed a valued attribute, they performed at levels comparable to men and to women in the no-threat control condition. In Study 2, men and women worked on a spatial rotation test and were told that women were stereotyped as inferior on such tasks. Approximately half the women and men self-affirmed before beginning the test. Self-affirmation improved the performance of women under threat, but did not affect men's performance.
\end{abstract}




\section{Combating Stereotype Threat: \\ The Effect of Self-affirmation on Women's Intellectual Performance}

A growing body of research on stereotype threat has demonstrated that stereotypes not only exert their influence by affecting how people are perceived and treated, but also by directly affecting those to whom they apply. According to Steele and his colleagues (Steele \& Aronson, 1995; Steele, Spencer, \& Aronson, 2002), stereotypes can constrain behavior when a member of a stereotyped group is placed in a situation in which poor performance could be evaluated as evidence that the individual possesses stereotypic group deficiencies. This situational "stereotype threat" then may disrupt the individual's performance and produce the feared deficient performance.

In an initial test of this idea, Steele and Aronson (1995) demonstrated that African Americans, a group stereotyped as intellectually inferior, performed significantly worse on a difficult verbal ability test compared to white students, but only when the test was described as a measure of intelligence. Thus, participants underperformed when placed in a situation that made relevant their negatively stereotyped identity. This finding has since produced a flurry of research demonstrating that relevant stereotypes can diminish performance of members of other stereotyped groups, such as women (Brown \& Josephs, 1999; Inzlicht \& Ben-Zeev, 2000; Shih, Pittinsky, \& Ambady, 1999; Spencer, Steele, \& Quinn, 1999), the economically underprivileged (Croizet \& Claire, 1998), black and white athletes (Stone, Lynch, Sjomeling, \& Darley, 1999) and White men (Aronson et al., 1999).

However, less work has focused on how individuals might overcome the threat. In one study, African American college students appeared to overcome consequences of their negative intellectual stereotype - they received better grades and were more engaged in school — when they were encouraged to view intelligence as malleable instead of an ability that cannot be modified (Aronson, Fried, \& Good, 2002). Two sets of studies also suggest that stereotype threat performance deficits can be alleviated when people think about members of their stereotyped group who are competent role models (Marx \& Roman, 2002; McIntyre, Paulson, \& Lord, 2003). The studies we present join these efforts and investigate the efficacy of self-affirmation as a psychological strategy that might work to alleviate the performance deficits found under stereotype threat.

Self-Affirmation

According to self-affirmation theory (Steele \& Liu, 1983; Steele, 1988), achieving and maintaining self-integrity and a sense of self-worth is a primary source of human motivation. Furthermore, consistent with early theory and research on compensatory processes (e.g., Allport, 1961; Murphy, 1947), self-affirmation theory proposes that there is a great deal of flexibility in the way people can achieve the need to see themselves as decent, moral, and competent when faced with information that would imply otherwise (e.g., Steele, Spencer, \& Lynch, 1993). Research derived from self-affirmation theory has shown that defensive reactions to situations that pose a threat to self-integrity can be reduced or eliminated by focusing on an alternative path to meeting overarching self-esteem needs (i.e., self-affirming). Following self-affirmation, for example, people seem less concerned with failure on a purported intelligence test (Koole, Smeets, van Knippenberg, \& Dijksterhuis, 1999), are less apt to rationalize behavior through attitude change (Steele \& Lui, 1983), and are more open to acknowledging threats to personal health and mortality (Sherman, Nelson, \& Steele, 2000). In sum, self-affirmation findings are consistent with the idea that self-integrity is fundamental - that when threatened, it is not the 
particular threat per se that is the problem, but the implications of the threat for one's global sense of self-integrity (Steele, 1988).

In like fashion, a threatened sense of self-integrity is also posited to be a crucial component in generating stereotype threat. As Steele, Aronson and others have noted (e.g., Aronson, Quinn, \& Spencer, 1998; Steele et al., 2002), stereotype threat is a phenomenon most likely to affect individuals whose self is invested in the stereotyped performance domain. Consistent with this idea, Stone et al. (1999) found that White participants who were told that a task was diagnostic of an ability for which they were negatively stereotyped ("natural athletic ability") performed worse than participants in the control condition only if general performance in athletics was important to their sense of identity. Research by Aronson et al. (1999; Study 2) also reported a similar identification effect with White men in the domain of math ability.

When linked to self-integrity, performance is likely imbued with exaggerated significance and so the possibility of failure is of exaggerated concern. Under stereotype threat, people's sense of competence and integrity is threatened from the outset as their behavior, if less then perfect, might be construed and judged in a stereotypic and negative light. And it is this threatened sense of self-integrity that is most likely their undoing. The mechanism or process by which performance deteriorates may be due to any number of, or combination of phenomena, such as reduced working memory capacity (Schmader \& Johns, 2003), arousal (O'Brien \& Crandall, 2003), apprehension (Aronson et al., 1999), or implicit anxiety. But the point we wish to make is that at its inception, stereotype threat comes from a threat to self-integrity, from the stereotype implying one's potential for inferiority or incompetence. Thus, we wished to determine whether stereotype threat effects could be reduced or eliminated by attacking its apparent root with a self-affirmation induction. We hypothesized that by directly addressing the need to maintain a sense of self-integrity through affirming a valued characteristic that is not under threat, we would reduce or eliminate the impact of the stereotype threat, allowing people to more fruitfully deal with the situation and perform better.

\section{Study 1}

Study 1 was designed to test whether self-affirmation would eliminate decrements in women's math performance resulting from the threat posed by the negative stereotype that women are mathematically inferior. In order to test this hypothesis, male and female students completed a difficult math test under one of two stereotype threat conditions. In the control condition, participants completed a math test framed as a non-diagnostic measure. In the stereotype threat condition, participants completed the same difficult test framed as a measure of math intelligence. To assess whether self-affirmation would reduce the effect of stereotype threat on performance, one group of women under stereotype threat was given the opportunity to affirm a valued attribute before taking the test. A second group under stereotype threat served as a comparison for the intervention strategy and wrote about an attribute they did not value before taking the test. We predicted that women who were self-affirmed would perform as well as women not under stereotype threat.

\section{Participants and Design}

\section{Method}

The participants were 77 female and 70 male introductory psychology students who completed the study for partial course credit. Female participants were randomly assigned to one of three conditions: a non-diagnostic test control condition, a stereotype threat condition, and a stereotype threat/self-affirmation condition. ${ }^{1}$ We also included two male comparison conditions: the non-diagnostic control and the stereotype threat condition. 
Based on past research and our theoretical understanding of stereotype threat we selected participants based on two a priori selection criteria. First, following stereotype threat research with the same population also investigating women and math performance (Schmader, 2002; Schmader \& Johns, 2003), to minimize the potential for a floor effect, we selected participants who scored at least 500 on the quantitative section of the SAT (or the equivalent on the ACT, as converted by ACT). Secondly, also following stereotype threat research with the same population (Schmader \& Johns, 2003), we selected only those participants who knew the stereotype concerning females and math because it was these women whose performance we expected to be most affected by stereotype threat. This selection criterion was particularly important because the stereotype was never made explicit to participants in this experiment (as has been done in other research, e.g., Spencer et al., 1999; Blascovich, Spencer, Quinn, \& Steele, 2001), and pre-testing revealed that a substantial percentage of our subject pool reported no knowledge of the stereotype.

Because participants were recruited using sign-up sheets, we were unable to apply the selection criteria prior to participation. As a result, it was necessary to run more participants than were included in our final sample. SAT scores were acquired directly following the test as was knowledge of the stereotype with two questions: "Are you aware of the stereotype about women and math?" and "What is the stereotype?" Nineteen women and 39 men did not meet our criteria as they either answered "No" to the first question or failed to describe the stereotype correctly. An additional 26 women and 4 men did not meet our SAT criterion. Our final sample consisted of 32 women and 27 men.

\section{Materials and Procedure}

Experimental sessions took place in a classroom and were run in mixed-sex groups ranging from 4 to 15 participants. A white male experimenter began each session with a brief introduction. This introduction served as the primary manipulation of stereotype threat. In the non-diagnostic control condition the experimenter informed the participants they would "work on some reasoning problems" that were being pilot tested for future studies. The experimenter explained that he was interested in getting "people's impressions of the problems" afterwards and encouraged the participants to "make a strong and genuine effort" while completing the test. In the stereotype threat condition, the experimenter informed the participants that they would work on some reasoning problems and that the study was concerned with "math and reasoning abilities". Furthermore, the test was described as a direct measure of math intelligence.

Participants were encouraged to make a strong and genuine effort on the test in order to allow for an accurate evaluation of their "abilities and limitations".

Participants were then given a "preliminary form" that served as the vehicle for the threat reduction strategy (i.e., self-affirmation). Women who heard the stereotype threat introduction were randomly assigned to one of two conditions: self-affirmation or non-affirmation control. The male participants (regardless of the threat instructions) and women in the non-diagnostic control were all given a non-affirmation control packet.

Self-affirmation was manipulated using procedures based on those employed in past research by Sherman et al. (2000) and Fein and Spencer (1997). The participants were instructed to rank order a list of 11 "characteristics and values" in order of personal importance. The items included characteristics such as sense of humor, creativity, physical attractiveness, social skills, and relations with friends/family. After ranking, participants in the self-affirmation condition were instructed to write about why their most valued characteristic (the item ranked "1") was personally important and describe a time when it had been particularly important to them. 
Participants in the non-affirmation control condition were instructed to write about why their ninth most important characteristic was important to other people and describe a time when it had been important to others.

Participants were administered the math test after completing their preliminary form. The test consisted of 16 multiple-choice word problems adapted from the Graduate Management Test (GMAT). In all conditions, the cover page of the test contained brief instructions informing participants that they would have 20 minutes to complete the problems. The instructions also informed participants that we would assess the total number of problems answered correctly and so they should attempt to answer as many questions as possible. In the stereotype threat conditions the cover page displayed the label "Quantitative Examination" and included a space for participants to record their gender.

Following the test, participants completed a brief form that assessed stereotype knowledge, SAT (or ACT) scores, and gender. Once the final questionnaire was completed, participants were debriefed and thanked.

\section{Results and Discussion}

Performance on the math test was measured as the total number of questions participants answered correctly. We analyzed performance using a one-way analysis of variance. The five conditions were: female- and male-non-threat control, female- and male-threat, and female-threat + self-affirmation. This omnibus test was significant, $F(4,54)=7.70, p=.001$. $^{2}$ This effect was analyzed further using simple effects analysis. As predicted, women in the stereotype threat condition $(M=3.60)$ performed worse compared to women in the non-threat control condition $(M=5.70), p=.05$ and men in the stereotype threat condition $(M=8.31), p<.01$. The performance of men in the non-threat control condition $(M=8.09)$ was not significantly different from the performance of men in the stereotype threat condition, $p>.8$.

Having established the basic stereotype threat effect, we conducted a pair-wise test to assess our primary prediction that self-affirmation would eliminate the effect of stereotype threat on women's math performance. This analyses revealed that women under stereotype threat who self-affirmed $(M=6.42)$ outperformed women in the pure stereotype threat condition $(M=3.60)$, $p<.01$. The means are displayed in Figure 1 .

\section{Study 2}

The results of Study 1 provided support for the hypothesis that self-affirmation works to alleviate stereotype threat performance deficits. However, limiting these findings, many participants were eliminated from the data analysis because they did not meet our selection criteria - they did not report knowing the stereotype or did not score above 500 on their math SATs. It is possible that these participants differed in ways other than the reasons they were selected out for.

For example, we might have eliminated people who in fact knew the stereotype but did not want to admit it. Perhaps they did not want to appear sexist or did not want to perpetuate the stereotype by acknowledging it explicitly. However, we did collect supplementary data from the same subject pool indicating that for women, such acknowledgment does not covary with social desirability scores (Marlowe \& Crowne, 1964), $r(40)=-.01, p>$.9. Although perhaps not surprisingly, for men, greater social desirability does predict lesser acknowledgement of the stereotype, $r(15)=-.71, p<.01$. However, perhaps women's knowledge of the stereotype was unconscious and so they could not verbally express it. Whatever the case, we excluded 5 women who scored above 500 on their math SAT from the stereotype threat condition because they did 
not report the stereotype, and these women performed at levels comparable to those not under threat (mean performance score of 6.4). Thus, this question may be meaningful for stereotype threat, and future work might be directed at investigating how different levels of stereotype knowledge (e.g., conscious, unconscious), or how different beliefs about the stereotype, can affect vulnerability to stereotype threat performance decrements.

Although these are certainly promising questions for future research, we wished to avoid these issues in Study 2 and continue our focus on the effects of self-affirmation on stereotype threat. Consequently, rather than trigger the threat in a similar covert way and rely on activation of participants' prior knowledge of the math stereotype, we instead triggered the threat more explicitly in a new performance domain, that of mental rotation, by directly telling female participants that they were negatively stereotyped in this domain. Although probably less prevalent than the math stereotype, there is evidence of a cultural belief that women are inferior to men in spatial ability (see e.g., Deaux, 1985).

A second limitation of Study 1 was its inability to address one question relevant to our hypothesis - whether the palliative effects of affirmation provided specific stereotype threat relief, or whether it simply provided a general performance boost. The design of the first study did not completely test our theoretical analysis that this treatment was easing a specific selfthreat imposed by the negative stereotype, versus simply enhancing performance for reasons not related to the threat. It is possible that self-affirmation generally enhanced performance but for reasons that have nothing to do with the psychology of stereotype threat.

One way to distinguish this "general boost" possibility from our specific "stereotype threat" hypothesis would be to provide the opportunity for men, who did not show performance deficits under female stereotype threat conditions, to self-affirm before completing the primary performance task. If men do not show enhanced performance but women do, then we can be more confident that the effect of self-affirmation is not a general increment in performance but is directly countering the deficit that stereotype threat would produce otherwise. We therefore sought to replicate the stereotype threat and affirmation finding but with an additional condition in which men also affirmed before taking the test. We predicted that self-affirmation, while boosting performance for women under stereotype threat, would not boost performance for men.

\section{Method}

\section{Participants and Design}

Fifty-five female and 55 male introductory psychology students completed the study for partial course credit. They were randomly assigned to one of two conditions: a stereotype threat condition or a stereotype threat plus self-affirmation condition. Data from 4 participants (1 woman in threat, 1 woman in affirmation, and 2 men in threat) were not analyzed because they did not understand the test instructions as indicated during the debriefing and because they did not answered the test questions as the directions indicated. Our final sample consisted of 52 women and 53 men.

\section{Materials and Procedure}

Participants were run in a classroom in mixed-sex groups ranging from 2 to 16 people. A white male experimenter began each session with a brief introduction that served to induce stereotype threat. The experimenter informed participants that they would work on a spatial rotation test and that the study was concerned with various factors involved in spatial intelligence. The experimenter told them that after the test they would receive feedback to give them an idea of their strengths and weaknesses on this kind of task. The experimenter added "For instance, one thing we'll look at is how men and women differ in their performance on the test, 
and how true the stereotype is, or the generally held belief is, that women have more trouble with spatial rotation tasks". In this way we induced stereotype threat by explicitly telling female participants that they were stereotyped as deficient in spatial rotation ability. The experimenter then explained that the test would be challenging, and that this was necessary to accurately evaluate people's abilities and limitations in order to better understand the factors involved in both. The experimenter closed the introduction by asking the participant to make a strong and genuine effort when taking the test.

As in Study 1, participants were then randomly assigned one of two versions of a "preliminary form", which served to manipulate self-affirmation. Once all the participants completed the preliminary form, the experimenter administered the spatial rotation test. This test was the Vandenberg and Kuse (1978) Mental Rotation Test, refurbished under the guidance of M. Peters (Peters, Laeng, Latham, Jackson, Zaiyouna, \& Richardson, 1995). The cover page displayed the label "Spatial Ability Test" and included a space for participants to record their name and gender. There were 24 items, each consisting of a target figure and four comparison figures. Two of the four comparison figures were always rotated versions of the target figure, while the other two were always different than the target. The participants were instructed to rotate the figures in their mind in order to figure out and mark the two options they believed matched the target. Furthermore, they were told that for an item to be correct, both correct options needed to be marked. Before beginning the test all participants were guided through a practice page. The experimenter then explained to participants that they would have only 12 minutes to work on the test and to work as quickly as possible without sacrificing accuracy.

Once the 12 minutes expired, the experimenter asked all participants to put their pencils down and to put the test in an envelope. The experimenter then passed out a final form that assessed SAT/ACT scores, GPA, and gender. Once this questionnaire was completed, participants were debriefed and thanked.

\section{Main analyses}

\section{Results and Discussion}

To test our a priori predictions, we conducted two planned comparisons on the mean number of items answered correctly. To test whether women who affirmed under threat scored significantly higher than women under threat who did not affirm, we weighted women's noaffirmation stereotype threat mean with a -1 , women's affirmation mean with a 1 , and all other condition means with a 0 . In support of our prediction, this contrast was significant, $t(70)=2.19$, $p<.05^{3}$-women who affirmed got more items correct $(M=10.05)$ than women who did not affirm $(M=13.44)$. We also tested whether men who affirmed scored higher than men who did not, using the same contrast weights. Consistent with our hypothesis, this test was not significant, $t(70)=.67, p>.5$. (Ms of 14.24 and 13.13, respectively). Thus, as depicted in Figure 2, the results suggest that self-affirmation boosted the performance of women under threat but did not boost the performance of men (who were not under stereotype threat).

In sum, Study 2 generated stereotype threat in the performance domain of spatial rotation, and with a slightly different manipulation than in Study 1. We told participants they were negatively stereotyped, and thus eliminated the stringent selection criteria used in Study 1 adopted to handle the concern that participants might not know the stereotype. We also showed again that self-affirmation completely alleviated the effects of stereotype threat. Specifically, women led to believe that they were negatively stereotyped in this domain performed worse unless they were given the opportunity to affirm themselves. Furthermore, affirmation did not 
boost performance for men. This supported our prediction that self-affirmation would addresses stereotype threat, but would not provide a non-specific boost to men's performance.

\section{General Discussion}

We examined the ability of self-affirmation to reduce the performance impairment resulting from conditions that arouse stereotype threat. Consistent with past stereotype threat research, we found in Study 1 that women who completed a difficult math test under stereotype threat performed significantly worse compared to those not under stereotype threat. More importantly, we also found that women under stereotype threat who were induced to affirm one of their most valued characteristics before the test were able to correctly answer as many questions as non-threatened women.

In Study 2 we replicated the finding in the performance domain of spatial rotation. Women were led to believe that they were negatively stereotyped in this domain, and they performed worse unless they were given the opportunity to affirm themselves. Additionally, affirmation did not boost performance for men (who were not under stereotype threat). This suggests that self-affirmation is effective by counteracting the threat generated by the negative stereotype rather than simply enhancing test performance. However, we cannot be definitive about this because it is conceivable that these male participants were affirmed even in the noaffirmation condition because the manipulation implied that they were targets of a positive stereotype. Thus, it is possible affirmation would boost performance for men not under stereotype threat but who were perhaps nevertheless concerned about the implications of poor performance for their self-integrity. However, we obtained no evidence of this here, even though there was clear room for additionally improved performance on the test given that the mean for non-affirmed men was less than 14 out of a possible 24 correct.

From the self-affirmation perspective in conjunction with the present findings, we can suggest that whatever the mediating psychological factors (e.g., cognitive load, working memory capacity, arousal, anxiety, suppression, etc.) that may cascade from the threat, the negative effects on performance produced by stereotype threat stem first and foremost from a threat to one's self-integrity. For example, perhaps self-affirmation, by securing the self, eases a need to push away and suppress negative stereotype-relevant thoughts (Spencer, 2003), which in turn frees cognitive resources such as working memory capabilities (Schmader \& Johns, 2003) to allow for improved performance. As Steele, Spencer, and Aronson (2002) suggest, however, the mediators of stereotype threat effects might vary as a function of both the stereotype and the performance domain. But despite these potential differences, the source of the problem seems the same-stereotype threat presents a direct challenge to people's self-integrity.

Nevertheless, challenges to people's self-integrity under stereotype threat may come in different forms. For example, under stereotype threat, concerns about performance, concerns about how others will evaluate one's self, and concerns about how others will evaluate one's group, might all play a role in diminishing performance. The current studies cannot speak to the possibility that self-affirmation worked to soothe some forms of self-threat more than others. However, research has consistently demonstrated that self-affirmation procedures ameliorate a wide variety of self-threats (e.g., Steele \& Liu, 1983; Sherman, Nelson, \& Steele, 2000; Koole, Smeets, van Knippenberg, \& Dijkesterhuis, 1999). Thus, it seems likely that self-affirmation should successfully combat whatever form of self-integrity threat is operating in stereotypethreatening situations. If a threat to self-integrity is at the heart of stereotype threat, then negative stereotypes should lose their power to threaten - regardless of the route they generally take to exert their detrimental effects - when the self is secured through affirmation. 
If this is the case, self-affirmation theory may provide a basic framework for understanding many of the factors that moderate stereotype threat effects, and for understanding other tactics that have been applied to alleviating these effects. For instance, several studies have shown that the relevance of, or investment in the stereotyped domain, moderates stereotype threat effects (Aronson et al., 1999; Leyens, Desert, Croizet, \& Darcis, 2000; Stone et al., 1999). From a self-affirmation perspective, relevance and investment may moderate stereotype threat in as far as they make the negatively stereotyped performance relevant for people's self-integrity. If a domain or performance is not relevant to one's self-integrity, then the negative stereotype cannot pose a meaningful threat to integrity.

Similarly, tactics that have been shown to ameliorate stereotype threat seem to do so by limiting the implications or relevance of the stereotype for people's self-integrity. For instance, viewing a negatively stereotyped ability as malleable (e.g., intelligence; see Aronson, Fried, and Good, 2002) greatly constrains the implications of the stereotype, and the implications of fulfilling that stereotype, for one's self. Consequently, this malleability perspective reduces the stereotype's potential to threaten self-integrity. In another example, allowing people the opportunity to attribute the possibility of poor performance to external causes (e.g., Brown \& Josephs, 1999; Stone et al., 1999) can ease concerns about one's own integrity and competence that the stereotype would otherwise exacerbate. In yet another example, providing competent role models in non-stereotyped domains (McIntyre, Paulson and Lord, 2003) can likely re-affirm the potential for competence in other important dimensions of value and in turn lessen the stereotype's ability to challenge one's feeling of self-integrity. Further, from this perspective, we should also expect that other and forthcoming methods for eliminating stereotype threat effects will be more or less effective to the extent that they protect or secure people's sense of selfintegrity from the implications of poor performance in the stereotype domain.

The primary motivation for this research was increasing our understanding of how members of stigmatized groups can begin to deal with the very real prospect of stereotype threat. It appears that self-affirmation before a stereotype-relevant task might be helpful in diminishing the impact of the situational threat placed upon members of stigmatized groups. Advising students taking important exams to take a few minutes to think about what they most value may be useful. In addition, as other self-affirmation and stereotype threat work attests to, the routes to securing self-integrity are likely plentiful. However, further research should be examine how these techniques fare in more real world settings and when they are more self-initiated. It is hard to say what would occur if people knew they were self-affirming only to ease a threat. The success of self-affirmation does, however, seem to support the notion that having diverse sources of self-esteem can buffer against the threatening effects of stigmatization (Crocker \& Major, 1989). Self-affirmation theory proposes that in order to reduce threat in a given domain it is important to self-affirm in an unrelated domain (Aronson, Blanton, \& Cooper, 1995). Thus, narrowly investing in one domain to the exclusion of others effectively reduces opportunities to ease threats by self-affirming. Further research could examine these issues.

The long run hope, of course, is that the influence of stigmatizing cultural stereotypes can be reduced or eliminated and circumstances can be created that do not condemn the targets of stereotypes before they have a chance to act. Unfortunately, these equalizing conditions are very infrequent. Standardized testing situations rarely allow members of stigmatized groups to perform in an environment free of the pressure generated by cultural expectations. Rarely do people make a concerted effort to dismantle stereotypes, to nurture rather than hamper those who are stigmatized. For this reason it is critical to understand the ways in which those who are at risk 
can enact strategies to overcome stereotype threat effects. Hopefully this in itself will eventually contribute to the erosion of those stereotypes. The current research suggests that the strategy of self-affirmation may provide a small step in this direction. 


\section{References}

Allport, G.W. (1961). Pattern and growth in personality. New York: Holt, Rinehart \& Wonston. Aronson, J., Blanton, H., \& Cooper, J. (1995). From dissonance to misidentification: Selectivity in the self-affirmation process. Journal of Personality and Social Psychology, 68, 986996.

Aronson, J., Fried, C. B., \& Good, C. (2002). Reducing effects of stereotype threat on African American college students by shaping theories of intelligence. Journal of Experimental Social Psychology, 37, 1-13.

Aronson, J., Lustina, M. J., Good, C., Keough, K., Steele, C.M., \& Brown, J. (1999). When White men can't do math: Necessary and sufficient factors in stereotype threat. Journal of Experimental Social Psychology, 35, 29-46.

Aronson, J., Quinn, D. M., \& Spencer, S. J. (1998). Stereotype threat and the academic underperformance of minorities and women. In J. K. Swimm, \& C. Stangor (Eds.), Prejudice: The target's perspective (pp. 83-103). San Diego, CA: Academic Press.

Blascovich, J., Spencer, S. J., Quinn, D., \& Steele, C. M. (2001). African Americans and high blood pressure: The role of stereotype threat. Psychological Science, 12, 225-229.

Brown, R. P., \& Josephs, R. A. (1999). A burden of proof: Stereotype relevance and gender differences in math performance. Journal of Personality and Social Psychology, 76, 246257.

Crocker, J., \& Major, B. (1989). Social stigma and self-esteem: The self-protective properties of stigma. Psychological Review, 96, 608-630.

Croizet, J., \& Claire, T. (1998). Extending the concept of stereotype threat to social class: The intellectual underperformance of students from low socioeconomic backgrounds. Personality and Social Psychology Bulletin, 24, 588-594.

Crowne, D.P., \& Marlowe, D. (1964). The approval motive: Studies in evaluative dependence. New York: Wiley.

Deaux, K. (1985). Sex and gender. Annual Review of Psychology, 36, 49-81.

Fein, S., \& Spencer, S.J. (1997). Prejudice as self-image maintenance: Affirming the self through derogating others. Journal of Personality and Social Psychology, 73, 31-44.

Inzlicht, M., \& Ben-Zeev, T. (2000). A threatening intellectual environment: Why females are susceptible to experiencing problem-solving deficits in the presence of males. Psychological Science, 11, 365-371.

Kirk, R. E. (1995). Experimental design: Procedures for the behavioral sciences. Pacific Grove, CA: Brooks/Cole.

Koole, S.L., Smeets, K., van Knippenberg, A., \& Dijkesterhuis, A. (1999). The cessation of rumination through self-affirmation. Journal of Personality and Social Psychology, 77, 111-125.

Leyens, J., Desert, M., Croizet, J., \& Darcis, C. (2000). Stereotype threat: Are lower status and history of stigmatization preconditions of stereotype threat? Personality and Social Psychology Bulletin, 26, 1189-1199.

Marx, D. M., \& Roman, J. S. (2002). Female role models: Protecting women's math performance. Personality and Social Psychology Bulletin, 28, 1183-1193.

McIntyre, R. B., Paulson, R. M., \& Lord, C. G. (2003). Alleviating women's mathematics stereotype threat through salience of group achievements. Journal of Experimental Social Psychology, 39, 83-90.

Murphy, G. (1947). Personality. New York: Harper \& Brothers. 
O'Brien, L.T., \& Crandall, C.S. (2003). Stereotype threat and arousal: Effects on women's math performance. Personality and Social Psychology Bulletin, 29, 782-789.

Peters, M., Laeng, B., Latham, K., Jackson, M., Zaiyouna, R., \& Richardson, C. (1995). A redrawn Vandenberg and Kuse mental rotations test: Different versions and factors that affect performance. Brain \& Cognition, 28, 39-58.

Schmader, T. (2002). Gender identification moderates stereotype threat. Journal of Experimental Social Psychology, 37, 32-44.

Schmader, T., \& Johns, M. (2003). Converging evidence that stereotype threat reduces working memory capacity. Journal of Personality and Social Psychology, 85, 440-452.

Sherman, D.A.K., Nelson, L.D., \& Steele, C.M. (2000). Do messages about health risks threaten the self? Increasing the acceptance of threatening health messages via self-affirmation. Personality and Social Psychology Bulletin, 26, 1046-1058.

Shih, M., Pittinsky, T. L., \& Ambady, N. (1999). Stereotype susceptibility: Identity salience and shifts in quantitative performance. Psychological Science, 10, 80-83.

Spencer, S.J. (2003). Media images and stereotype threat: How activation of cultural stereotypes can undermine women's math performance. Paper presented at the annual meeting of the Society for Personality and Social Psychology, Universal City, CA.

Spencer, S. J., Steele, C. M., \& Quinn, D. M. (1999). Stereotype threat and women's math performance. Journal of Experimental Social Psychology, 35, 4-28.

Spielberger, C.D., Gorsuch, R.R., \& Lushene, R. (1970). The State-Trait Anxiety Inventory (STAI) test manual. Palo Alto, CA: Consulting Psychologist Press.

Steele, C.M. (1988). The psychology of self-affirmation: Sustaining the integrity of the self. In L. Berkowitz (Ed.) Advances in experimental social psychology (Vol. 21, pp. 261-302). New York: Academic Press.

Steele, C. M., \& Aronson, J. (1995). Stereotype threat and the intellectual test performance of African Americans. Journal of Personality and Social Psychology, 69, 797-811.

Steele, C.M., \& Liu, T.J. (1983). Dissonance processes as self-affirmation. Journal of Personality and Social Psychology, 45, 5-19.

Steele, C. M., Spencer, S. J., \& Aronson, J. (2002). Contending with group image: The psychology of stereotype and social identity threat. In M. Zanna (Ed.), Advances in experimental social psychology (Vol. 34, pp. 379-440). NY: Academic press.

Steele, C.M., Spencer, S.J., \& Lynch, M. (1993). Self-image resilience and dissonance: The role of affirmational resources. Journal of Personality and Social Psychology, 64, 885-896.

Stone, J., Lynch, C. I., Sjomeling, M., \& Darley, J. M. (1999). Stereotype threat effects on black and white athletic performance. Journal of Personality and Social Psychology, 77, 1213 1227.

Vandenberg, S.G., \& Kuse, A.R. (1978). Mental rotations, a group test of three-dimensional spatial visualization. Perceptual \& Motor Skills, 47, 599-604. 


\section{Footnotes}

1. We also included another condition not relevant for this present paper in which participants expressed their negative emotions before the upcoming test.

2. The data from one participant was dropped from the analysis based on Kirk's (1995) recommendation concerning extreme scores. This participant's score exceeded the mean by 2.5 standard deviations. With this score included in the analysis the results of the ANOVA remain significant, $F(4,54)=4.38, p<.01$, and the overall pattern of means is unchanged.

3. We also computed a 2(male vs. female) X 2(no affirm vs. affirm) ANOVA with number of items correct as the dependent variable. Both the gender and affirmation main effects approached significance, $F(1,67)=2.76, p=.1$, and $F(1,67)=3.78, p=.06$, respectively. The interaction was non-significant, $F(1,67)=.973, p=.33$. Further, we tested the significance of the between factors variance not accounted for by the significant contrast. This effect was not significant, $F(1,67)=2.72, p>.1$. 


\section{Figure Captions}

Figure 1. Mean number of questions answered correctly by participant gender and stereotype threat condition.

Figure 2. Mean number of questions answered correctly by participant gender and stereotype threat condition. 



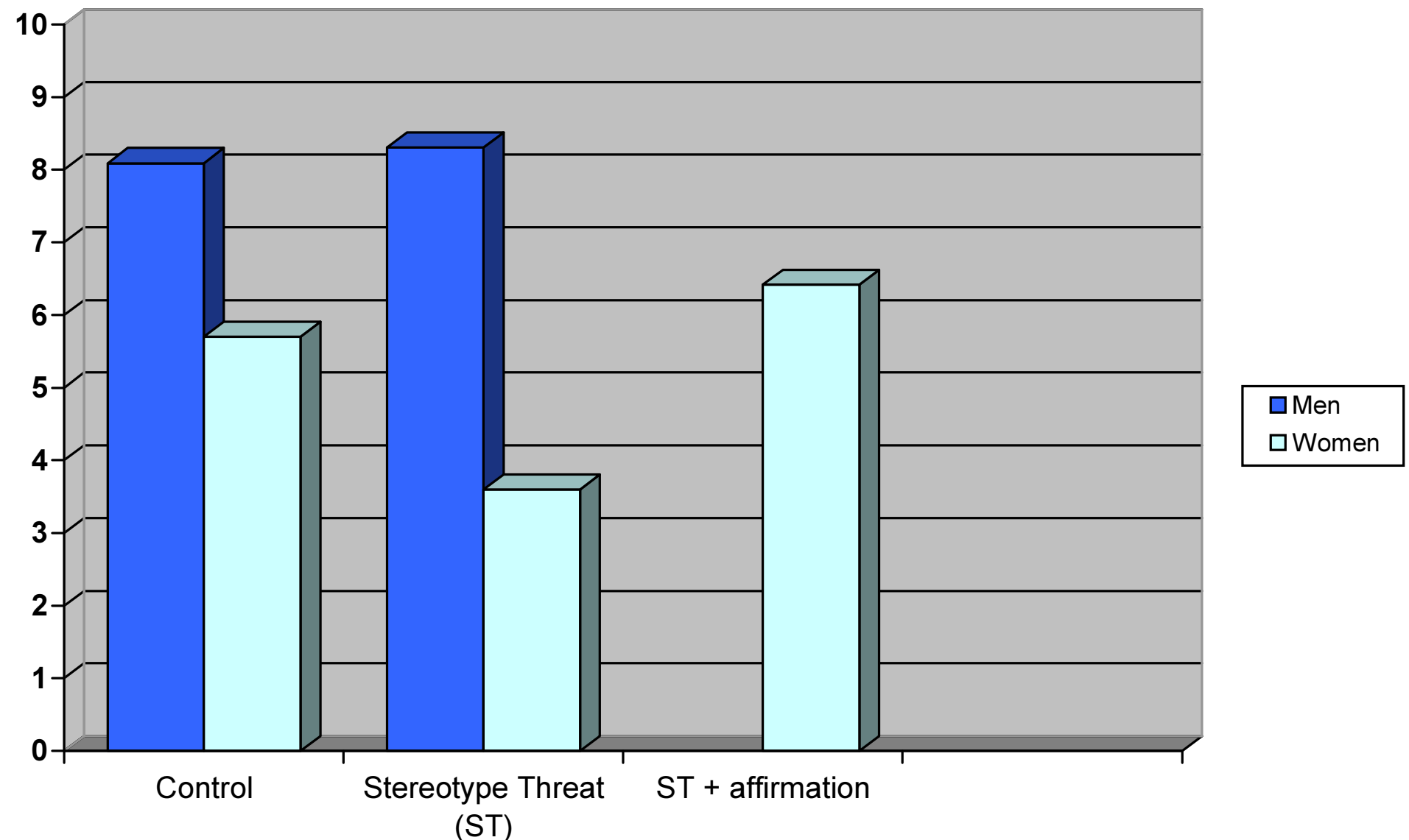




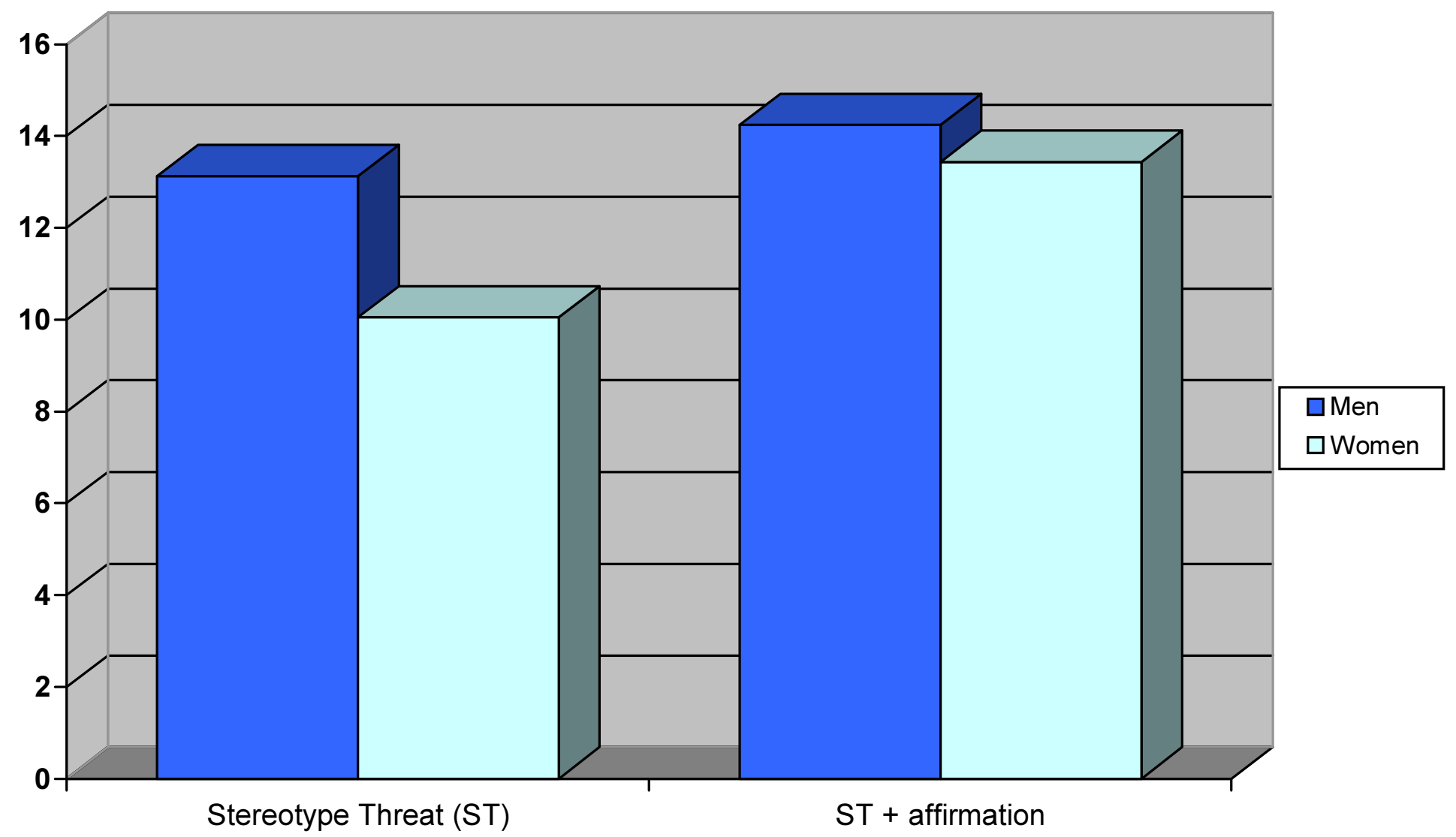

